أثر العقاقير المضادة للصرع على العمليات المعرفية للأطفال

$$
\begin{aligned}
& \text { إعداد } \\
& \text { إيمان عبد الفتاح محمود أحمد زيان } \\
& \text { طالبة دكتور اه } \\
& \text { قسم علم النفس كلية البنات } \\
& \text { إثراف }
\end{aligned}
$$

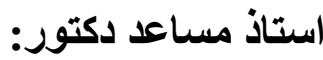

محمد عبد الهادى محمد

استاذ طب المخ و الأعصاب المساعد

كلية طب الأزهر بنين

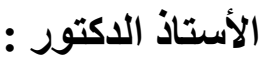

نبيلة أميـن أبـو زيــــ

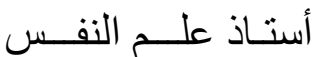

كلية البنات- جامعة عين شمس

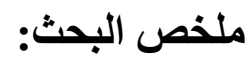




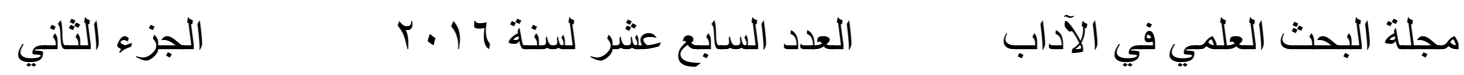
تؤثربعض العقاقير المضادة للصرع بالسلب على الوظائف المعرفية للأطفال فهى تعد أحد العوامل غير المباثرة التى يمكن أن تؤثر على العديد من الوظائف المعرفية خاصة الانتباه و الذاكرة.

وتهدف الدراسة الحالية إلى الكثف عن الأثر السلبى للعقاقير المضادة للصر ع على الوظائف المعرفية. تألفت عينة الدر اسة من(• (1) أطفال يعانون من صر التر على الفص الصدغى يتر اوح سنهم

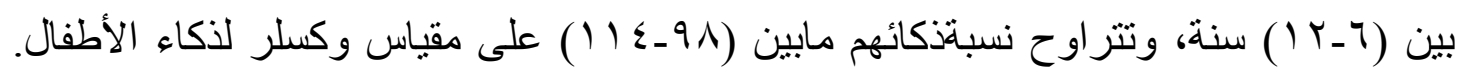
وأسفرت النتائج عن وجود فروق دالة بين منوسطى رتب القياسين القبلى و البعدى لدى ألى أفراد المجموعة . 


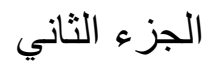

AAntiepileptic drugs have a negative impact on cognitive function in children, that is one of the indirect factors that can affect many cognitive functions specially attention and memory.

The aim of the present study was to detect the negative impact of antiepileptic drugs on cognitive function. The study sample consisted of (10) children suffering from temporal lobe epilepsy ,aged (6-12 years), their IQ was Ranging from(98-114) on a scale Wechsler Intelligence for children. The findings resulted in statistically significant differences between the averages of two measurements arranged prior and subsequent to the members of the group. 


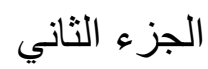

الصر ع حالة مرضية تصيب الأطفال و الكبار على حذ سو اء، وهى حالة ليست نـادرة. لكن

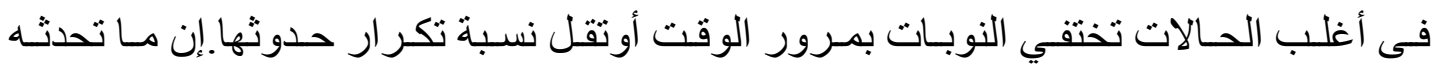

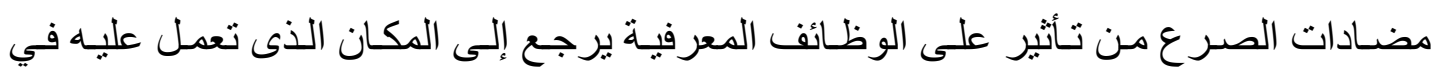

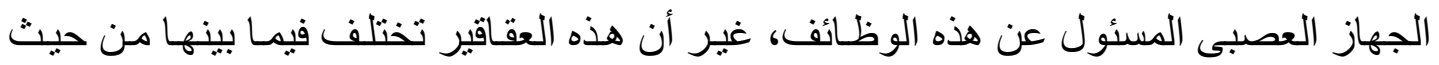

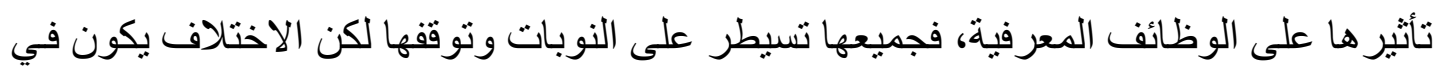
درجة تأثير ها على تلأك الوظائف.

مشكلة الاراسة :من خلال الاطلاع على الأبحاث السابقة والخبرة الذاتية في التعامل مع

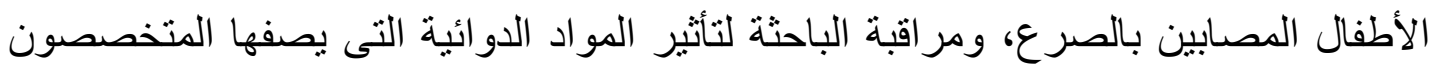

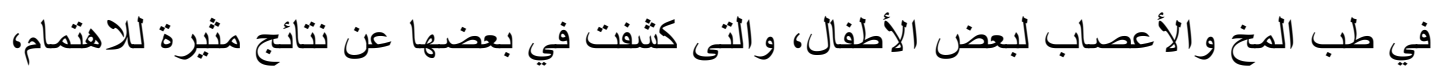

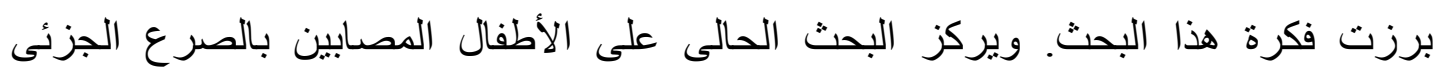

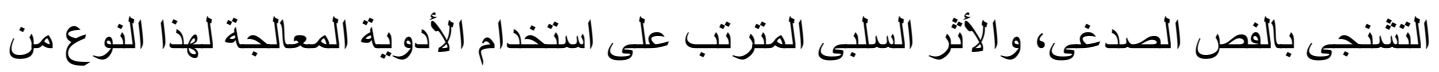

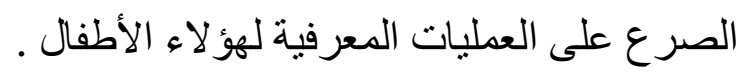

وقد لاحظت الباحثة أثناء عملها أن الأطفال الذين يتم علاجهم بمضسادات الصرع يتحسن

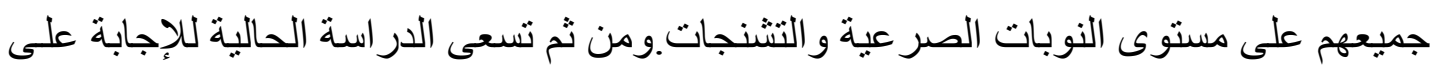

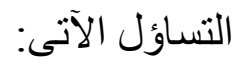

هل توجد فروق فى المستوى المعرفي لدى الأطفال المصابين بالصرع قبل وبعد

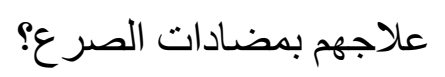

هدف الدراسة: الكثفف عن الأثر السلبى للعقاقير المضادة للصرع على الوظائف المعرفية.

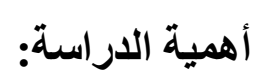

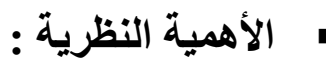

ندرة الدراسات العربية - فى حدود علم الباحثة ـ التى اهتمت بالكثف عن الأثر السلبى

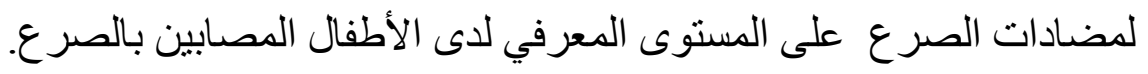

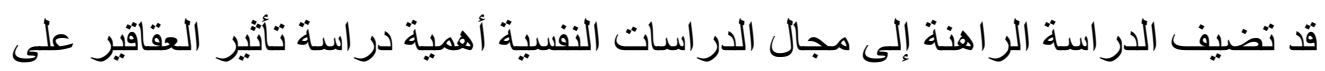

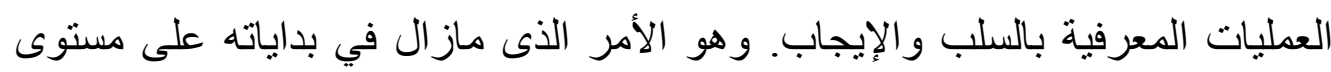

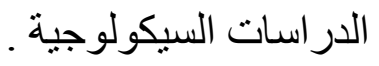




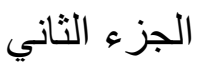

بعد الكثف عن الآثر السلبى لمضادات الصرع يمكن توجيه نظر الباحثين فى المجال السيكولوجى لمساعدة الأطفال المصابين بالصرع على تتمية العمليات المعرفية لديهم لتمكينهم من الاستفادة فى مختلف أنشطة الحياه. بعد الانتهاء من الدراسة الراهنة يمكن الإضافة إلى أهمية دور الأخصائى النفسى في

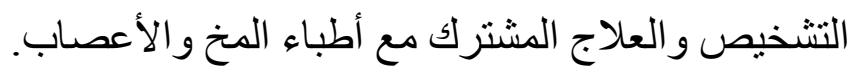
مفاهيم الاراسة:

- العلاج الاوائى Medical treatment: تعرفه الباحثة إجرائيا بأنه: جرعات دوائية (التجريتول) التى يصفها الطبيب للأطفال للسيطرة على نوبات الصرع. تعنه

\section{- العمليات المعرفية}

تعرفها الباحثة إجرائياً بأنها: مقدار التغير فى مستوى الذكاء الذى يكثف عنه كل من

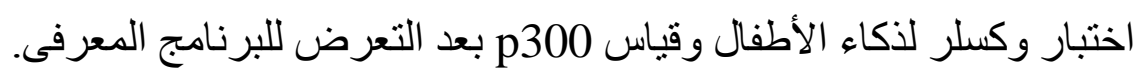

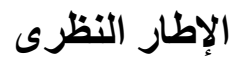

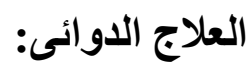

هو استخدام العقاقير فى إحداث تغيير كيميائى يؤدى إلى تغيير فى الانفعال، ويعد العقار نموذجياً إذا ما تو افرت فيه المواصفات التالية:

$$
\begin{aligned}
& \text { 1ـ أن يخفف الأعر اض فى أقل وقت ممكن. } \\
& \text { r- أن يفيد جميع المرضى أو أغلبهر. } \\
& \text { ك- كا يسبب إدماناً. }
\end{aligned}
$$

ـ ـ لا تقل استجابة المريض للعقار بمرور الوقت و الاستخدام.

هـ ليس ساماً فى حدود الجرعة العلاجية. 7ـ أعر اضه الجانبية قليلة فى حدود المسنطاع.

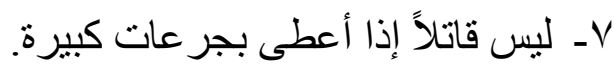

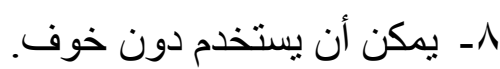

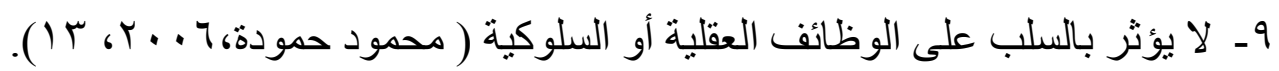


ومضادات الصر ع Anti epileptic drugs هى نوع من أنو اع العقاقير التى تعمل على التى

Meador et al., 2005,2108-(التوازن الكيميائى ما بين الإثارة والتثبيط للخلايا العصبية

وتتركز دراسة العلاج الدوائى فى المجال السيكولوجى بصورة كبيرة على دراسة العقاقير

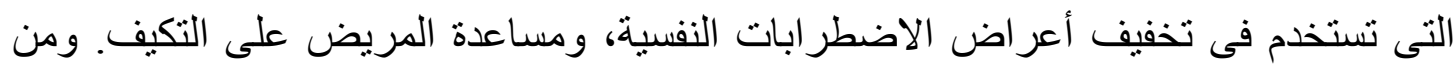

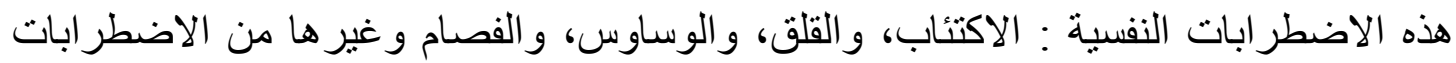

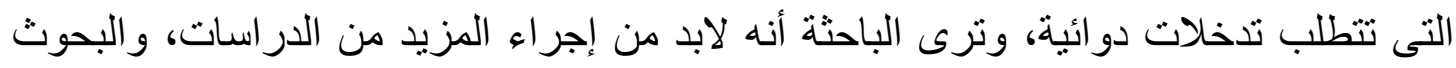

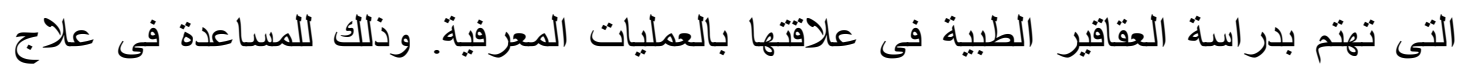
الاضطر ابات المؤثرة على هذه العطليات المعرفية.

"ولكى يمكن فهم آلية عمل العقاقير لابد لنا من معرفة آلية عمل الدماغ من خلال عمل الخلايا

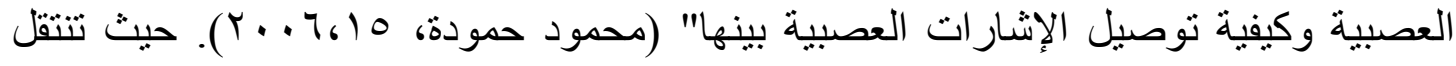
الاستثارة العصبية إما مبانرة عن طريق جريان تيار كهربى من خلية إلى أخرى أو عن طريق الإنتان إفر از مادة كيميائية (الناقلات العصبية) تقوم بتغيير نشاط الخلية العصبية أو النسيج الذئى يليها، وتعد الوسيلة الأخيرة وهى انتقال الاستثارة العصبية عن طريق المواد الكيمبائية هى الطريقة

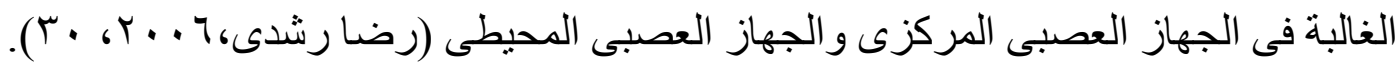
ويتكون المخ البشرى من ץ أجز اء رئيسية، يقوم كل منها بوظيفة منفردة وإن كان جميعها يقوم بهذه الوظائف فى تناغم مع الأجزاء الأخرى وتتثتمل الأجز اء الثثلاثة على : النصفان الكرويان،

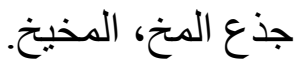

ويتحكم النصف الكروى الأيمن من المخ فى إدارة النصف الأيسر من الجسم والنصف الكروى الأيسر من المخ فى إدارة النصف الأيمن من الجسم. وتفسير ذللك هو انها يوجد منطقة

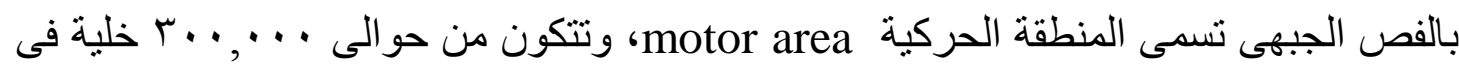
كل نصف. وتتجمع محاورها العصبية لتكون الحزم العصبية التى تعمل على تنبيه عضلات الجسم تسير كل حزمة عصبية فى كل نصف خلال أجزاء المخ حتى تصل إلى النخاع المستطيل

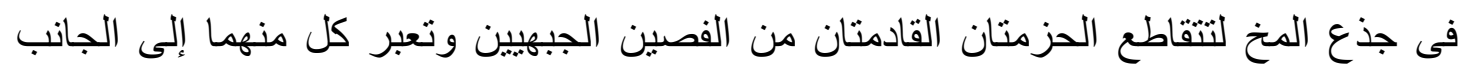
الآخر فى نهاية النخاع المستطيل حيث تعبر الحزمة اليمنى إلى الجهة اليسرى، بينما تعبر الحزمة اليسرى إلى الجهة اليمنى مكونة ما يسمى بالتقاطع الحركى و هى نفس النقطة التى يحدث

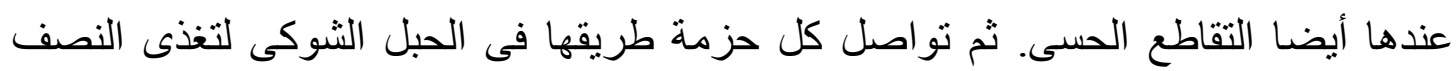


الجزء الثاني

المقابل لها من الجسم، لذايتحكم كل فص جبهى فى النصف المعاكس لله من الجسم نتيجة عملية التقاطع، و عند تلف أى جزء من المخ فإنه يؤثر على الجهة المقابلة له من الجسم (ألفت حسين، .$(\Sigma V 6 r \cdot 1 Y$

وتعرض الباحثة فى السطور الآتية اضطر اب الصر عنموذج لأحد الاختلالات التى تحدث بالدماغ وكيفية التعامل معها بالعلاج الدوائى.

\section{: Epilepsy (الصرع}

اتفق معظم الباحثين على أن الصرع عبارة عن اضطر اب في وظيفة المخ يصاحبه نوبات من تغير الإيقاع الأساسى للنشاط الكهربى للمخ، كما يصاحبه نوبات من اضطر اب بعض الوظائف الحسية أو الحركية أو النفسية أو الجسمية أوكلها معًا. وقد يصاحب ذلك نقص في مستوى الوعى يصل في بعض الأحيان إلى فقدان الوعى (سامى عبد القوى، ج . . ب). ويعرفه كل من "وليد عبد العزيز"، و "عبد الله الصبى" بأنه شحنات غير طبيعية صادرة من الجهاز العصبى تؤدى إلى توقف جميع الوظائف العصبية الطبيعية للإنسان (عبد الله الصبى و وليد عبد العزيز، ج + . ؟، 1 ( ).ويعرفه "فرج طه"بأنه أحد الأمراض العضوية التى تصيب المخ، ويتميز بأنه اضطراب

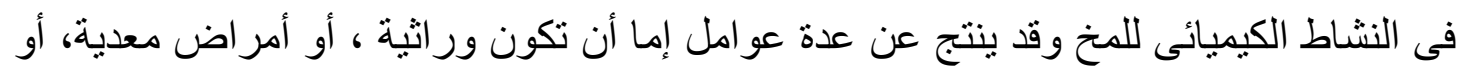

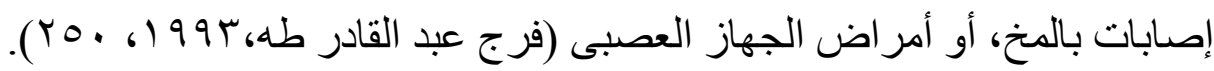

\section{التثنجات وكيفية حدوثها:}

التشنجات بأنو اعها المختلفة بما فيها التشنجات الصر عية تنشأ من أماكن مختلفة من المخ مما يؤدى لوجود أنواع مختلفة من الصرع و التشنجات ( أيمن الحسينى، 9، + . ب). وهناك ملايين من الخلايا العصبية في المخ متصلة ببعضها لتشكل حزم عصبية، هذه الحزم العصبية تتحكم في وظائف المخ، حيث تتحكم في الحركة والكلام والتفكير والإحساس والعاطفة.وقثرة المخ cerebral cortex وتنقسم إلى عدة فصوص (الفص الجبهى، الفص الصدغى، الفص الجدارى، الفص الخلفي)، ويقسم إلى جزئين أيمن وأيسر، عادة ما يكون أحدهما أكثر سيطرة من الآخر ويوجد بينهما روابط عصبية للتنسيق بينهما. وتعتبر القشرة الخارجية للمخ هى المصدر الرئيسى للثحنات الكهربية حيث تحتوى على الخلايا العصبية ومايتم بينها من تبادل الثحنات، وأى اضطر اب بها قد يؤدى إلى التشنج. ويحدث التشنج نتيجة شحنات كهربية غير عادية غالبا ماتصدر عن مجموعة من الخلايا في قثرة الدماغ وتتوقف نوع النوبة التشنجية على الجزء الذى صدرت منه 
الجزء الثاني

تللك الثحنات الكهربية لذلك يختلف نوع التشنج من حالة لأخرى ( عبد الله الصبى و ليد عبد

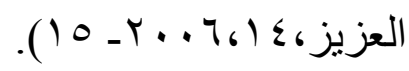

وكل خلية من خلايا المخ تؤثر في الخلايا المجاورة لها عن طريق عدد من العمليات الكيميائية، وكل خلية عصبية تحمل شحنة كهربائية تسرى خلال جسم الخلية إلى أطر اف ليفتها العصبية. ولا يوجد اتصال كهربى مباثر بين خلية وأخرى، لكن الثحنة الكهربائية تكون مصحوبة بإفرازمادة كيميائية تعرف بالموصل الكيميائى تنتشر عبر الحيز الضيق الذى يفصل بين طرف الليفة العصبية والخلايا المتاخمة له فيحدث شحنة كهربائية تؤدى إلى تنبيهها أو تثبيطها، لذلك فإن كل خلية من خلايا المخ تعتمد في وظيفتها على محصلة الآثار المنبهة، و المثبطة من كافة الخلايا المحيطة بها. فإذا ماتعرض عدد من الخلايا ذات الأثر المثبط للتلف مما يؤدى إلى تحرر الخلايا المتاخمة لها فتصبح مفرطة الإثارة، وتطلق شحنات منبهة تهيج عدداً آخر من الخلايا، وهذه بدورها تهيج خلايا أخرى لتفرغ شحنتها دون ضابط. وتسرى الثحنات الكهربية الثاذة في المخ بصورة سريعة، ويؤدى هذا الاضطراب الوظيفي إلى تولد أنماط مختلفة من النوبات الصر عية. وهذا ما يحدث ايضا إذا ماتعرضت الخلايا ذات الأثر المنبه فلكى إى تستوي وظائف المخ يجب أن يكون هنالك توازن مابين الإثارة والتثبيط(عبد اللطيف موسى،199 (، 9 9 ـ (1) ). وتحدث حالة اللاتوازن imbalance بين الإثارة والتثبيط في حالات التشنجات الجزئية partial seizurs بسبب تلف بالمخ ناتج عن أحد الأسباب الآتية:

$$
\begin{aligned}
& \text { - - نقص الأكسجين أثناء الو لادة . } \\
& \text { - التهاب الأغثية السحائية مثل الحمى الثوكية. } \\
& \text { - إصابات الر أس مثل السقوط و الحوادث. }
\end{aligned}
$$

- وجود نسيج غير طبيعى بالمخ مثل الأورام أو حدوث نشوه خلقي أثناء مرحلة نمو المخ. و قد لايكون هناك أي سبب و اضح. أما في حالات النشنجات العامة generalized seizurs فحالة اللاتوازن الكيميائى بين الإثارة والتثبيط تشغل جزءا كبيرا من المخ، وتختلف أسبابها عن أسباب التشنجات الجزئية باستثناء اسباب وجود أنسجة أوتركيات غير طبيعية بالمخ

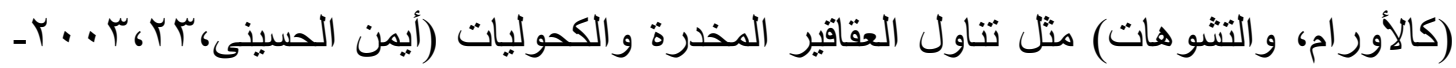

فالمؤثر ات العصبية تنتقل فيما بين الخلايا العصبية في اتجاهات محدودة وفق نظام دقيق، وذلك عن طريق الموصلات العصبية التى هى في الأصل مواد كيميائية طبيعية يفرزها المخ، وينتج 
الجزء الثاني

عن ذلك انتشار موجات كهرو كيميائية هى في الواقع شحنات كهربائية دقيقة تعطى إثارة تنتقل في اتجاهات معينة لأداء وظيفة ما، وليس ما يحدث من تشنجات حركية و عصبية في حالات الصرع سوى خلل يعترى طريقة انتشار هذه الشحنات الكهربائية وموضعها وشدتها ويؤدى في النهاية إلى حدوث النوبة. (لطفي الثربينى، 999 (1، 7؟ ).

ويرتبط الصرع بالعديد من مظاهر الاضطر اب التى تكاد تشمل الثخصية كلها سواء على . المستوى الثخصى أوالاجتماعى. وقد أثنار التراث العلمى إلى ارتباط الصرع بالعديد من الاضطر ابات النفسية كالقلق والاكتئاب و الفصام وسلوك اللامبالاه، أواضطر اب الوظائف العقلية مثل التذكر، وحل المشكلات مما يؤثر بشكل أو بآخر على الذكاء، والتحصيل الدراسى. وقد يثخص الصرع خطأ على أنه اى اضطر اب آخر مثل فرط النشاط، أو اضطر اب طيف التوحد Landau- أو الفصام الطفولى. فعلى سبيل المثال هناك متلازمة تدعى بمتلازمة (لانداو كليفنر (Kleffner syndrome هذه المتلازمة تبدو كثكل من أشكال فقدان القدرة على الكلام أو ما يعرف بـ (aphasia) و التي عادة ما تتطور بين ثناث وسبع سنوات. وتظهر لدى حوالى ؟ • \% من الأطفال المصابين بالصرع، ويفقد هؤلاء الأطفال قدرتهم على الاستيعاب أولا (اللغة الاستقبالية) ومن ثم القدرة على الكلام (اللغة التعبيرية)، و تحدث هذه التغيرات إما تدرجيا أو فجأة. والأطفال الذين يعانون من منتلازمة لانداو كليفنر لديهم نماذج شاذة و غير طبيعية نظهر في tempro- تخطيط الدماغ EEG في الفص الصدغي، وفي المناطق الصدغية الجدارية الققوية parieto-occipital الدماغ EEG للطفل أثناء النوم. وفى • ₹\% منهم تقريبا تظهر نوبات الصرع و هذه النوبات عادة Motwani et al., ما تكون غير متكررة بشكل رئيسي و تكون إما مع أو بدون التشنجات

وينبغي أن ينظر للصرع على انه عرض من أعراض الاضطرابات العصبية وليس مرض بحد ذاته ، ويستخدم مصطلح "الصرع" ليعكس هذا الاضطر اب ولا يعد مصطلح النوبة Seizure للصرع. فهناك العديد من الاضطر ابات تصاحبها نوبات ليست لها صلة بالصرع. مثل التشنجات الى تحدث للأطفال عند ارتفاع درجات حرارة أجسادهم، أيضًا التشنجات التى تحدث للأطفال نتيجة أمر اض التمثيل الغذائى، حيث بحدث اضطر اب في أملاح الجسم كالصوديوم و البوتاسيوم و الكالسيوم، لذلك لابد من التشخيص الفارق أى المقارنة بين هذه الحالات من خلال أوجه الثبه 
والاختلاف حتى نصل إلى التشخيص السليم. فإذا ظل هنالك شك يمكن اللجوء إلى بعض

$$
\text { الفحوص مثل رسم المخ (لطفي الثربينى، (999). }
$$

\section{علاقة الصرع بالتدهور المعرفي:}

تشير الدر اسات إلى وجود علاقة دالة بين الصرع خاصة صرع الفص الصدغى والتدهور المعرفي والذاكرة بصفة خاصة، ويؤثر صرع الفص الصدغى بالسلب على مستوى التحصيل الدراسى حيث أثـار هيرمان إلى أن صرع الفص الصدغى لايؤثر فقط على الذاكرة ولكن ايضا يؤدى إلى ضعف القدرات المعرفية بصفة عامة والذى يظهر على شكل ضعف التحصيل الدر اسى ومستوى الذكاء. حيث ينخفض مستوى الذكاء كلما كانت الإصـابة مبكرة وكثيرة التكر ار

وينقسم الفص الصدغى بالمخ إلى نصفان: نصف أيسر ، ونصف أيمن. تختلف مهام كل منهما عن الآخر، فالفص الصدغى الأيسر منوط بفهم اللغة ونتكيل الكلام، أما الفص الصدغى الأيمن فهو المسئول عن الذاكرة البصرية، وفهم العاطفة.أما المنطقة السفلية للقنرة الصدغية فهى المسئولة عن الذاكرة قصيرة المدى. فإذا حدثت إصابة أو خلل بتلك المنطقة يحدث خلل في التمييز البصرى مما يؤدى إلى عدم القدرة على الاختيار المناسب للمعلومات أو التغلب على Gordon et al., 1987, 330- تداخل المعلومات، أو القدرة على التحكم في التحديق المناسب

وهناك العديد من الاثار الناجمة عن إصابة الفص الصدغى مثل تغيرات في سمات الشخصية، و اضطر ابات انفعالية وعاطفية، وتراجع في الوظائف المعرفية كتدهور الذاكرة قصيرة المدى كما يلاحظ على من لديهم اصابات بالفص الصدغى سلوك اللامبالاه. و هنالك فروق بين إصابة الفص الصدغى الأيمن، و الفص الصدغى الأيسرحيث تتدهور الذاكرة الغير لفظية بعد اصابة الفص الصدغى الأيمن بينما تتدهور الذاكرة اللفظية والذكاء اللفظى بعد إصـابة الفص الصدغى الأيسر. وبالتالى يؤدى صرع الفص الصدغى الايسرإلى ضعف الذاكرة Helmstaedter, ) اللفظية،ويؤدى صرع الفص الصدغى الايمن إلى ضعف الذاكرة البصرية .(2001, Elger. et al. 2004 


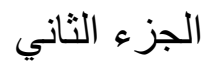

هنالك العديد من الأدوية التى تستخدم في علاج الصرع المعروفة باسم مضادات الصرع. ويهتم البحث الحالى بدراسة أحد هذه الأدوية من ناحية الآثار الجانبية وهو كاربامازيبين(المعروف تجاريا بتجريتول) حيث يعد من الأدوية شائعة الاستخدام في حالات الصرع الجزئي مثل صرع الفص الصدغي. ولابد من اتباع استراتيجية معينة عند سحب مضادات الصر ع، فهناك احتمالية تكر ار النوبات بعد وقف العلاج فى بعض الحالات. ولقد كانت القاعدة المعدول بها قديما تقضي بإمكانية وقف المعالجة الدوائية للصرع تدريجيا إن أمكن السبطرة على النوبات لمدة عامين متتاليين على الأقل. لكن حاليا أثبت عدم صحة هذه الاستر اتيجية لأن هناك أنماطا من الصرع كالصرع الحمبد لدى الأطفال المصحوب بتغيرات صر عية فى تخطبط كهرباء الدماغ صادرة من مركز المخ والفصين الصدغيين قد لا تحتاج إلي معالجة طويلة المدى لأنها تتوقف تلقائيا بعد تجاوز الطفل المرحلة العمرية التى تشيع خلالها. ومن جهة أخرى فإن هنالك بعض أنواع الصرع يلازم المريض طيلة حياته، وإن انضباط النوبات لدى المريض لا يعني شفاءه من المرض المزمن، فينبغي تجنب التوقف المفاجئ للدواء أو عدم تناوله بصورة منتظمة كى لا يتعرض لنوبات متكررة قد تودى بحياته. فهناك ما يعرف بالحالة الصر عية أو غمرة الصرع حيث يحدث التشنج أو سلسلة من التشنجات لأكثر من • r دقيقة، وهى حالة شديدة الخطورة قد تنتهى بالوفاه أوتلف المخ. وتتطلب سرعة نقل المريض للمستشفى لمعالجته بمضادات الصرع عن طريق حقن الوريد. كما قد يحدث أيضا توقف القلب و التنفس و هبوط ضغط الدم. و عادة تتراوح فترة سحب الأدوية المضادة للصر ع بين ستة أسابيع

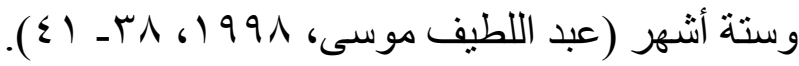

ويتمثل الهدف الأساسي لمضادات الصرع فى السيطرة على النوبات فى ضوء المستوي الأدني للأعر اض الجانبية المتوقعة. و عادة ما يبدأ الأطباء بوصف جر عات قلبلة تتبعها زيادة تدريجية لتجنب الآثار الجانية قدر الإمكان ( فيونا مارشال، باميلا كروفورد، ه . . ، بم).

\section{العمليات المعرفية:}

يتضمن النشاط العقلى عدة عمليات كالإدر الك، والانتباه، و التذكر، و التخيل، و التفكير و اللغة. ومع أن كلاً من هذه العمليات يتميز بخصائص معينة تفرق بين بعضها بعضًا إلا أنها فى نفس الوقت تتشابه وتتداخل فى خبرات الفرد وفى استجاباته العقلية لتشكل مايسمى بالأكاء. ويعرفها رافع وعماد الزغلول بأنها "جميع العمليات العقلية والتى تشمل كلا من الإحساس و الإدرالك والانتباه، و التعلم، و الذاكرة، و التفكير، و التخيل، و اللغة، و الذكاء، 


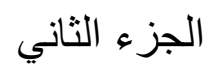

و العو اطف. والتى يمارسها الفرد عند استقباله للمعلومات ويعالجها ويرمز هـا ويخزنها ثم

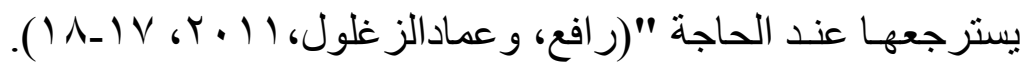

وتتضمن عملية معالجة المعلومات جميع العمليات المعرفية من انتباهوإدراك، وتعرف،وفهموتحليل،وتذكر،واتخاذ قرارات،واستجابة .وتتتم معالجة المعلومات بتوجيه

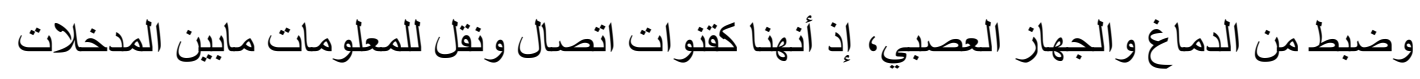
و المخرجات عبر الجهاز العصبي. وكل مرحلة من مر احل تكوين ومعالجة المعلومات تستقبل

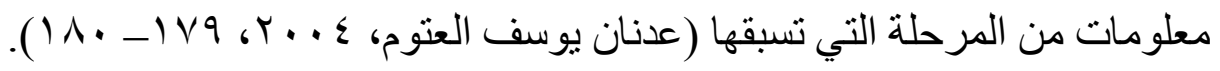

وتثمل العمليات المعرفية كلا من الأسلوب المعرفي cognitive style و القدرة المعرفية cognitive capacity لتشغيل المعلومات و عليه فإن مسئ الاستخدام يكون أكثر ميلا لتحليل المثير ات الادئ الادر اكية بطريقة غير طبيعية مثل تضخيم المثير stimulant augmentation وهذا الأسلوب له له علاقة بالاستعداد الدافعى الذى يتميز بالاندفاعية وعدم كف السلوك. وفهم الاسلوب المعرفي للفرد

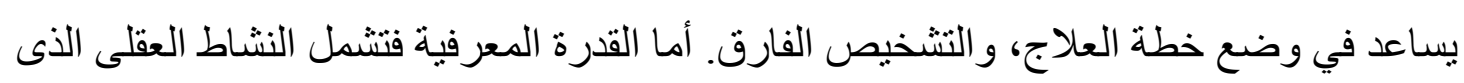

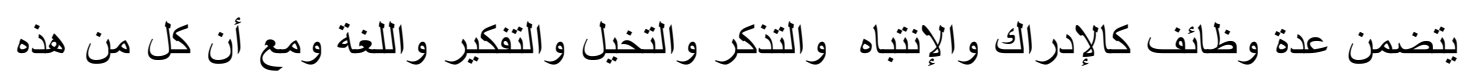

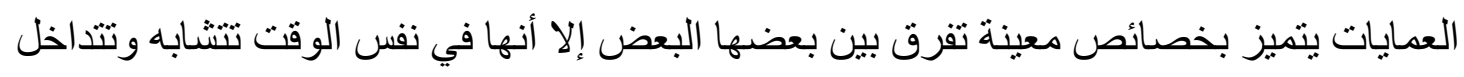

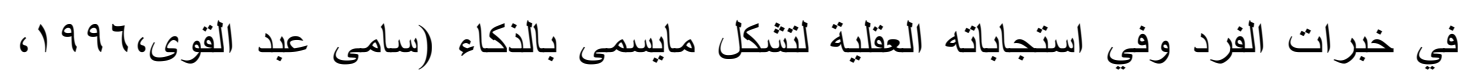
. (Y. .

الانتباه: يعتبر الإنتباه مكوناً من مكونات معالجة المعلومات لاى الإنسان ، ويعرف الإنتباه بصفة

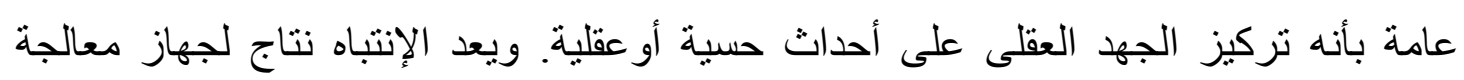

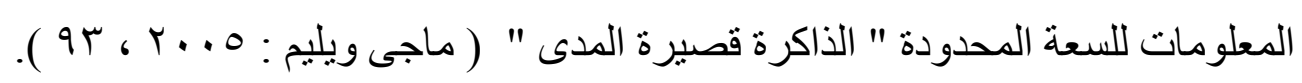

الإدراك : يعد الإدراك الدعامة الأولى للمعرفة الإنسانية، والإدراك الحسى هو إعطاء معنى

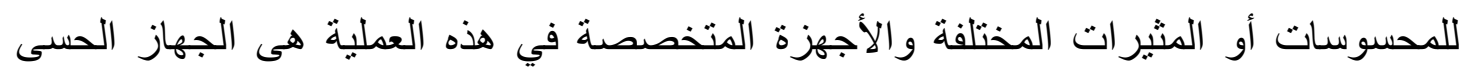
و الجهاز العصبى. والعوامل التى تثؤثر على عملية الإدراك لا تقتصر على الخبرة السابقة والبناء

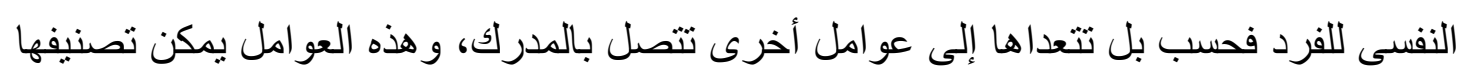

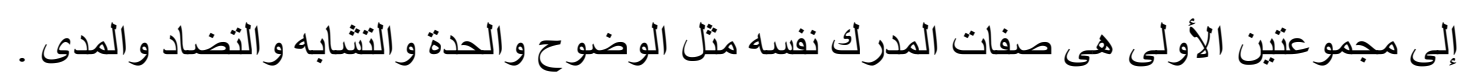

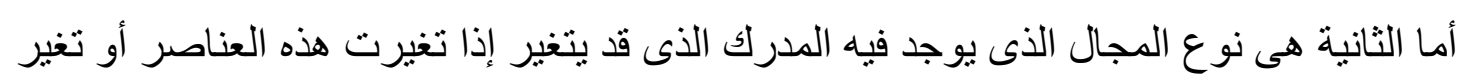

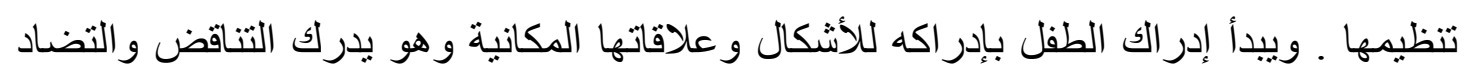


الجزء الثاني

قبل التشابه الذى يبدأ في الطفولة المتأخرة ، و يساعد هذا النوع من الإدراك على تعلم الحروف

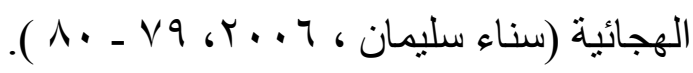

الأاكرة: اختلف الباحثون و العلماء في تعريف الذاكرة بإختلاف الإتجاهات النظرية و الفكرية لهم،

$$
\text { ومن أهم هذه التعريفات مايلى: }
$$

تعرف الذاكرة على أنها العملية العقلية التي يتم بها من تسجيل وحفظ و إسترجاع الخبرةالماضية

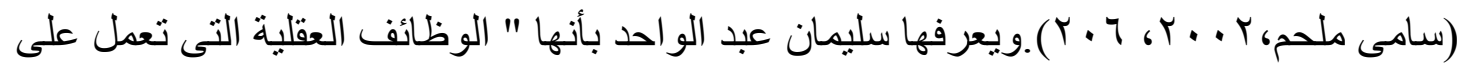
احتفاظ المرء بآثار خبرات الماضى واستعادتها أو الانتفاع بها فيمابعد، سواء على المستوى

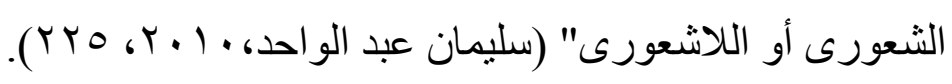

التذكر : تللك العملية العقلية التى يتمكن بها الفرد من استرجاع ما تعلمه سابقاً، ويبدأ التذكر عند الطفل بالناحية الذاتية ثم يتحول إلى الناحية الموضوعية ، ويكون تذكر الطفل مباشراً وآلياً. ويتأثر التذكر بميول الفرد و انفعالاته وقدرته على الإنتباه وخبراته المختلفة. ويختلف تعريف الذاكرة فى معناه عن تعريف التذكر، فإذا كانت الذاكرة هى احتفاظ وتخزين المعلومات و الحقائق فى العقل، فالتذكر هو جلب المخزون من المعلومات والحقائق من خلال عملية الاسترجاع، و لايكاد يخلو أى موقف فى الحياه من استخدام التذكر، لذلك له أهمية خاصة فى التفكير وسلوك

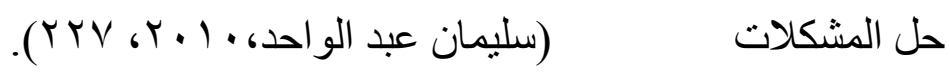

\section{دراسات سابقة : د}

دراسات تناولت العلاج الاوائى بمضادات الصرع:

أجرى الباحثون فى المجال الطبى، و الصيدلى دراسات عديده على مضادات الصر ع لمعرفة

الآثار الجانبية المترتبة على تناولها، خاصة تلك المرتبطة بتدهور العمليات المعرفية، ودر اسة أقلها تأثير ا على هذه العمليات فى محاولة منهم للحد من تلك الآثار الجانبية كما يتضح فى نتائج

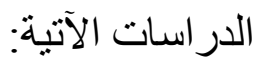

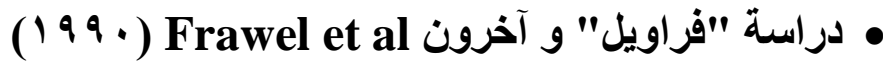
- هدف الدراسة: بث أثز ارتباط استخدام الفينوباربيتال بانخفاض معدل الذكاء لدى

الأطفال.

ـ عينة الدر اسة:تكونت عينة الدراسة من YIV طفل فى المرحلة العمرية مابين م شهور و وس شهرا بعانون من تشنجات حرارية، تم تقسيمه إلى عينتين تجريبية تعالج 
الجزء الثاني

"بالفينوباربيتال" (من مضادات الصرع)، و الأخرى ضابطة تم إعطائهم علاج وهمى وكانت الجر عات التى تعطى للأطفال ع ـ- مجم / كيلو جر ام. Placebo نتائج الدر اسة: تدنى متوسط ذكاء العينة التجريبية إلى ؟ •. درجة بالمقارنة بالمجموعة الضابطة، ثم تم قياس مستوى الذكاء مرة أخرى بعد ستة أشهر من السحب التدريجى للدواء فلوحظ تدنى متوسط الذكاء إلى ب.0 وخلصت فى دراستها إلى أن عقار الفينوباربينال يخفض الأداء المعرفى لدى الأطفال، وأن أثناره السلبية قد تدوم عدة أشهر بعد ايقافه.

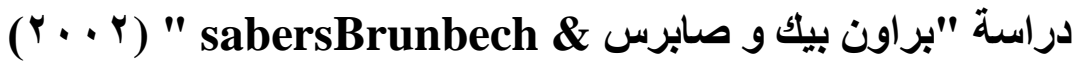

- - هدف الدر اسة: مقارنة بين آتار مضادات الصرع القديمة و الجديدة على العمليات المعرفية - نتائج الدر اسة: أشارت النتائج إلى أن مضادات الصرع الجديدة (مثل جابابتين، وبير امين) لها تأثير أقل من الأدوية القديمة المضادة للصرع على العمليات المعرفية خاصة الذاكرة و الانتباه.

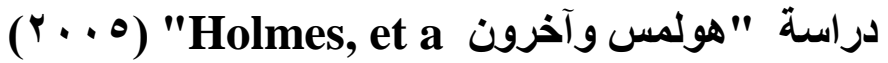

- هدف الدراسة: أثر تعرض الأمهات لمضادات الصرع أثناء الحمل على العمليات المعرفية لأطفالهن

- عينة الدراسة:تكونت عينة الدر اسة من ـ ـ طفلا لأمهات تعرضن لمضادات الصرع أثناء الحمل. ـ أدوات الدر اسة: تم استخدام عدة فحوصات تشمل فحوصات عقلية مثل اختبار الذكاء اللفظى و العملى، وأخرى جسمية مثل قياس محيط الر أس. - ـ ت نتائج الدراسة: خلصت تللك الدراسة فى نتائجها إلى أنه إذا تعرضت الأمهات أثناء الحمل للعلاج بمضادات الصرع فإن أبنائهن يعانون من انخفاض ملحوظ في معدل الذكاء، بالإضافة إلى احتمالية حدوث تشوهات أخرى لهؤلاء الأطفال قد تصاحب ذللك

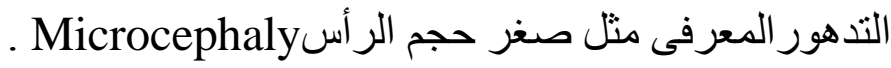

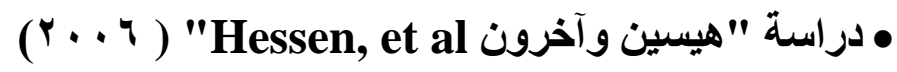
- هدف الدر اسة: بحث أثر سحب مضادات الصرع على العمليات المعرفية. - عينة الدراسة: تكونت عينة الدر اسة من ـ10 شخص تم علاجهم بمضادات الصرع خاصة (كاربامازيبين ، و الفالبروات). 
- - نتائج الدراسة: بعد السيطرة على التشنجات لمدة عامين متتاليين تم السحب التدريجى للاو اء

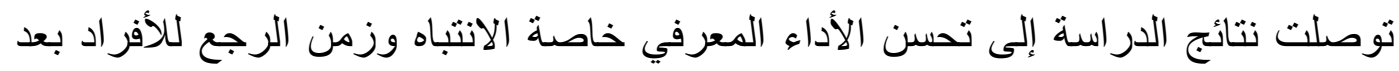

$$
\text { سحب مضادات الصرع. }
$$

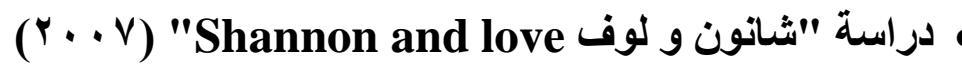

- هدف الدراسة: بحث أثز استخدام مضادات الصرع على العمليات المعرفية لدى الفئران.

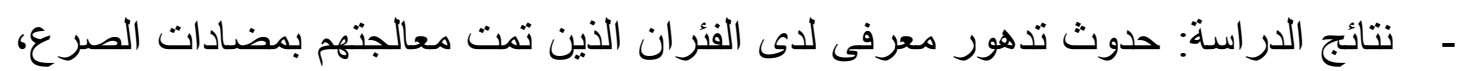

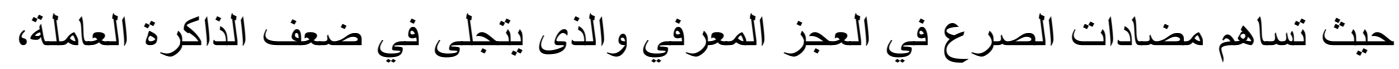
و الانتباه مما يؤثر بدوره على عملية التعلم.

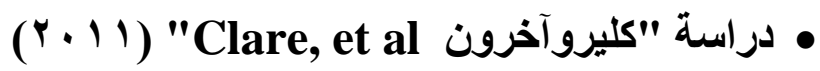

- هدف الدراسة: بحث اثر استخدام مضادات الصر ع على العمليات المعرفية.

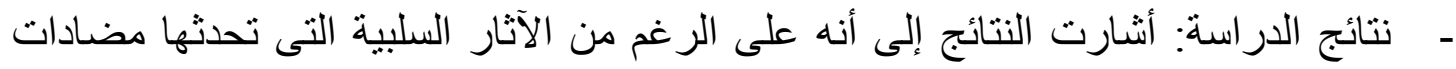

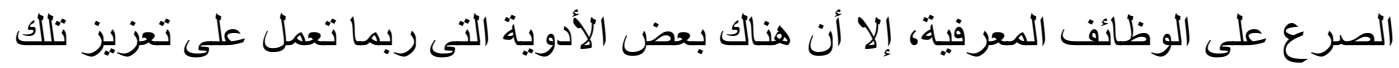

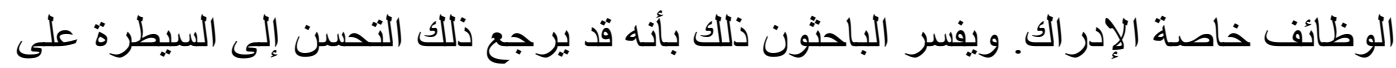

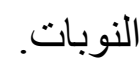

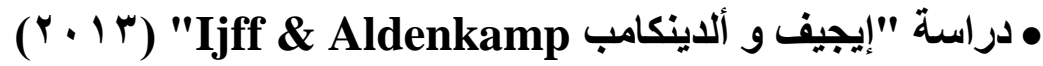
- هدف الدراسة: التعرف على الآثار المعرفية السلبية لمضادات الصرع مثل الفينوباربيتال، وكاربامازيين، وجابابتين، وفالبروات، و الفينيتوين، وتوبير اميت، لاموتريجين.

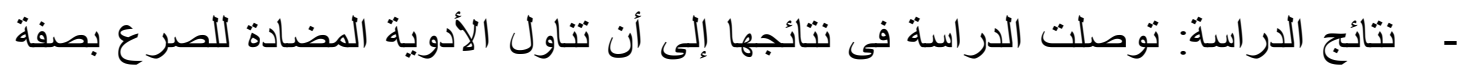
عامة لها تأثير سلبي على الجو انب المعرفية لاسيما الانتباه و الادر الك و الذاكرة.

• دراسة "براندت وآخرون (2014) Brandt, et al) - هدف الدر اسة: بحث أثر أحد مضادات الصر ع (توبر اميت) على العمليات المعرفية. - - عينة الدر اسة: جr مريضا يعانون من الصرع بالإضافة إلى الإعاقة العقلية.

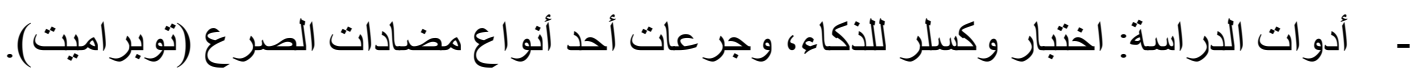

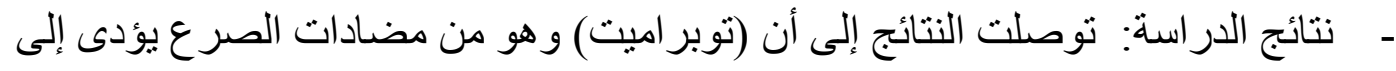
تدنى الأداء المعرفى وخاصة على مستوى الطلاقة اللفظية، ومدى الذاكرة، والذاكرة العاملة. وكذلك بعد سحب الدواء لوحظ انخفاض فى الذاكرة اللفظية، ومرونة الأداء المعرفى، والطلاقة اللفظية.

وعند مقارنة تنائج العينة أثناء تناولهم العلاج، بنتائجها بعد سحب الدواء توصل الباحثون

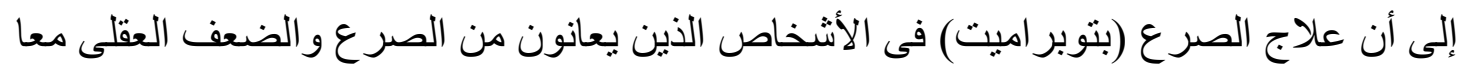




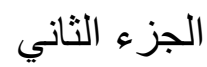

يؤدى إلى مزيد من التدهور المعرفى. وخلصت تللك النتائج إلى أن هذا الدواء قد يؤدى إلى

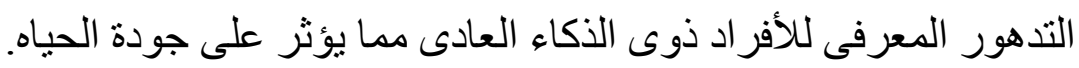

\section{ت تعقيب على الدراسات السابقة:}

من حيث الهذف: اتفقت الدراسات السابقة فى أهدافها فى التعرف على الآثار المعرفية

$$
\text { المترتبة على استخدام مضادات الصر ع فى علاج النوبات الصر عية. }
$$

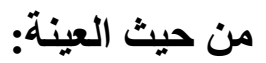

تنوعت الدراسات السابقة من حيث نوع العينة وحجمها، حيث أجريت بعض الدراسات السابقة

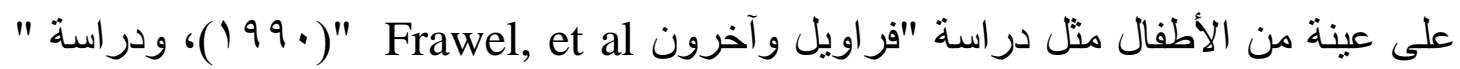

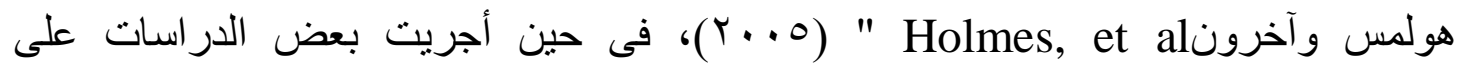
الأشخاص البالغين مثل دراسة " هيسين وآخرون Hessen, et al " (7 . . ب)، بينما أجريت

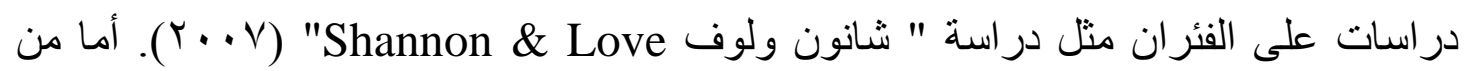

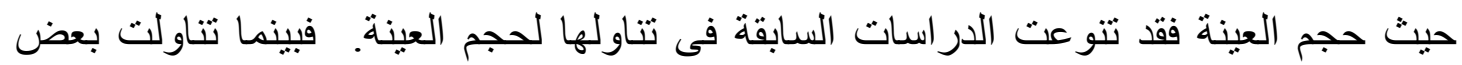

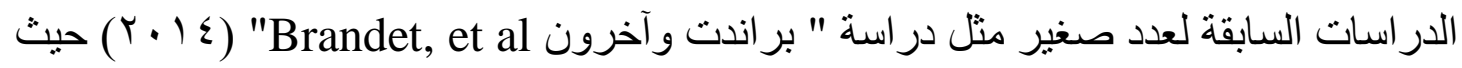

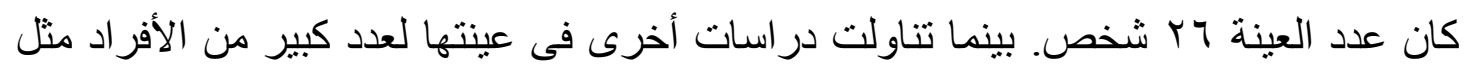

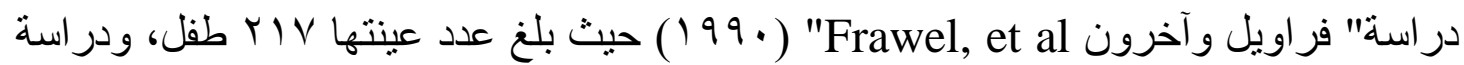

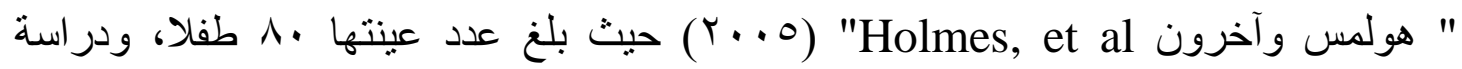

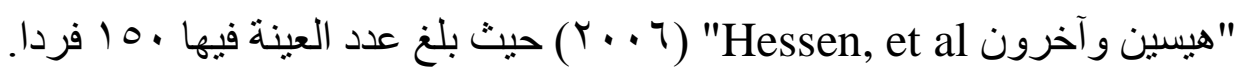

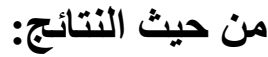

اختلفت الدر اسات السابقة فى نتائجها، فبينما تتفق نتائج معظمها إلى أن استخدام مضادات الصرع

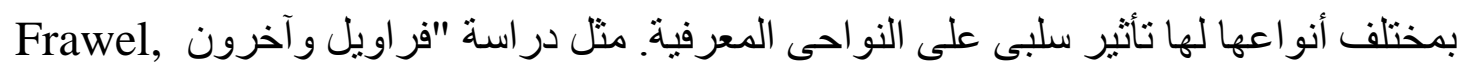

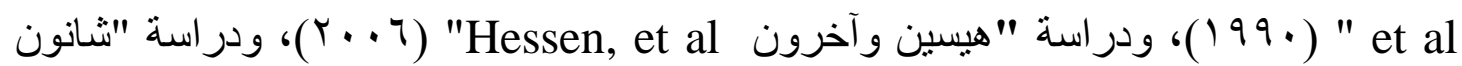

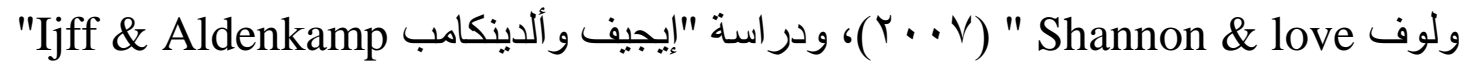

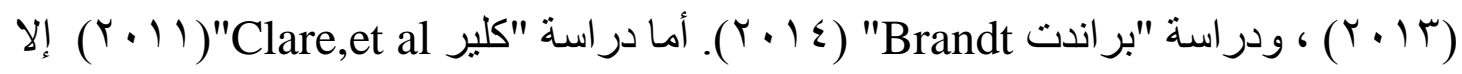

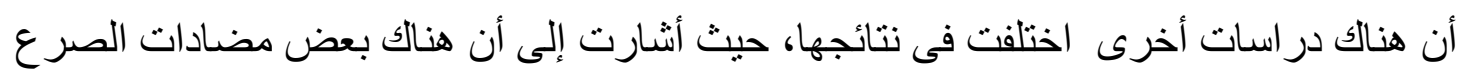

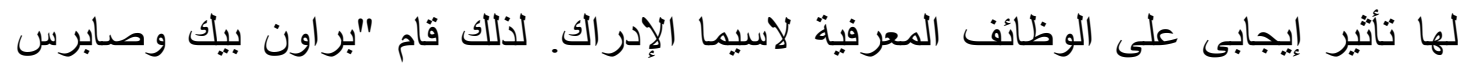
Brunbech \& Sabers 


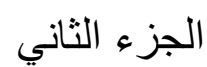

المعرفية ليشير ا فيها إلى أن مضادات الصرع الجديدة لها تأثير أقل من مضادات الصرع القديمة

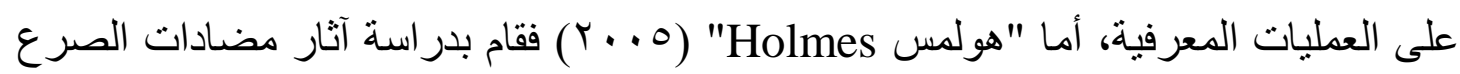
على الأمهات أثناء الحمل. فوجد أن أبنائهن يعانون من انخفاض في معدل الذكاء بالإضافة إلى لى تشو هات أخرى مثل صغر حجم الرأس. فرض الدراسة: بعد اطلاع الباحثة على الدراسات السابقتتم صياغة الفرض الآتى: توجد فروق فى المستوى المعرفي لاى الأطفال المصابين بالصرع قبل وبعد التدخل فى علاجهم بمضادات الصرع.

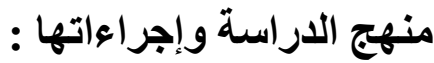

استخدمت الباحثة المنهج شبه التجريبى نظر اً لطبيعة الدراسة و أهدافها أيضًا لصعوبة التجريب

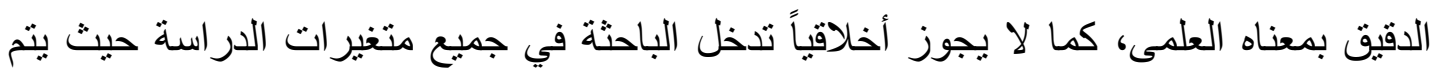

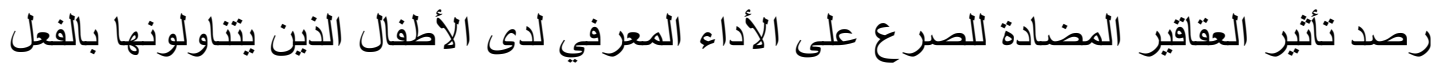
(بواسطة الطبيب ).حيث إن التحكم في المتغير المستقل في الدراسة الراهنة وهى العقاقير

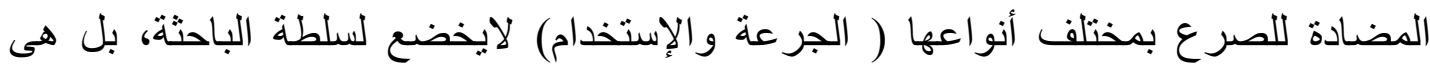
تجرى في سياقها الطبى وتقوم الباحثة برصد نتائجها من وقت لآخر ، و الإشارة إلى أكثر ها أمانا

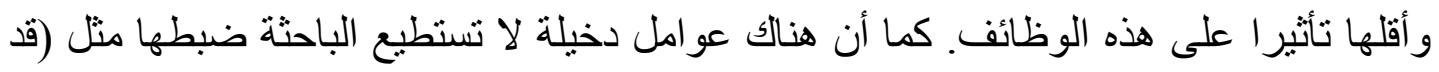

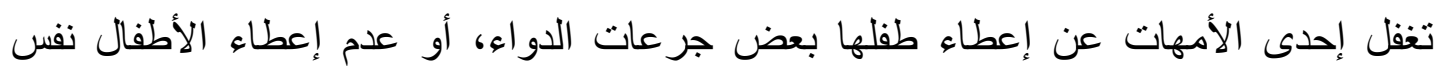

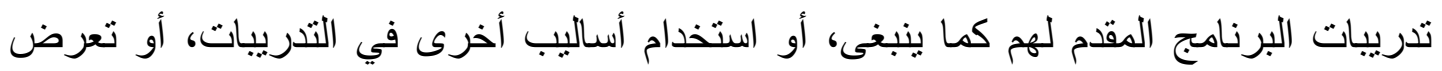

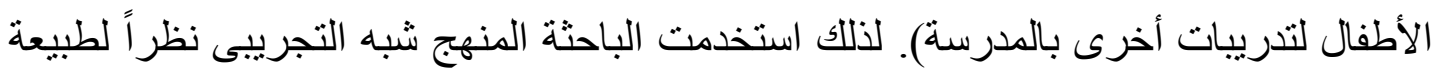

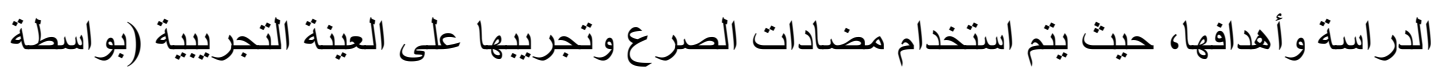
الطبيب). وهى تمثل المتغير المستقل في الدراسة الر اهنة (الجرعة والاستخدام لايخضع لسلطة

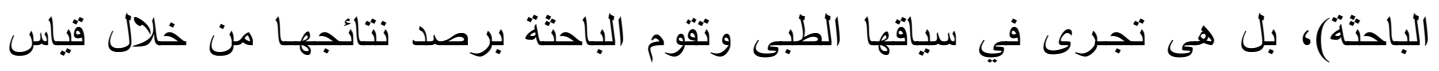

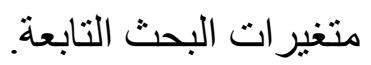

عينة الدراسة: تألفت عينة الدر اسة الحالية من(· • ) أطفال يعانون من الصرع الجزئى

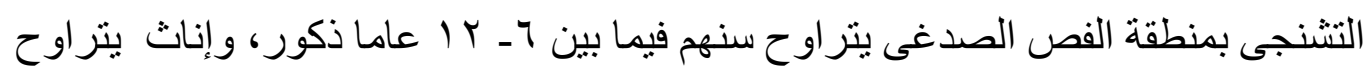
مستوى ذكائهم مابين ( 91 و ـ (1) (1) على مقياس وكسلر للأطفال. 


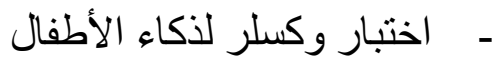
- اختبار كونرز لقياس مدى تشتت الانتباه وفرط الحركة لدى الأطفال ( قائمة تقدير الو الدين). "الجزء الخاص بتثتت الانتباه فقط" - - - مهاز رسم المخ (أداه تشخيصية فقط).

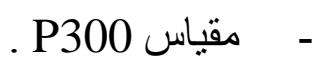

- مؤشر تلف المخ ( أداه تثخيصية فقط) (اقتباس الباحثة من مقياس وكسلر لذكاء الأطفال) - - برنامج علاجى دو ائى (تم تحديد الدواء و الجر عات بو اسطة الطبيب وتر اقب آثاره الباحثة). - دليل العو امل و الظروف المؤدية إلى نشأة الصر ع لدى الطفل (إعداد الباحثة).

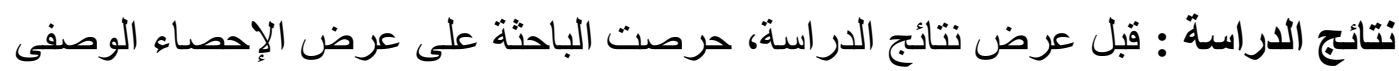
لمتغير ات الدر اسة فى الجدول الآتى:

جدول ( ) الإحصاء الوصفى لمتغير ات الدراسة

\begin{tabular}{|c|c|c|c|}
\hline \multicolumn{2}{|c|}{ المجموعة الضابطة } & \multirow[t]{2}{*}{ القياس } & \multirow[t]{2}{*}{ المتغيرات } \\
\hline الانحراف & المتوسط & & \\
\hline 5.70 & 104.50 & 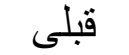 & \multirow[t]{2}{*}{ الذكاء } \\
\hline 2.31 & 92.30 & بعدى بع ل بعا & \\
\hline 61.72 & 305.27 & قبلى (قيلى & \multirow[t]{2}{*}{ P300 } \\
\hline 35.44 & 418.16 & بعدى & \\
\hline 7.321 & 65.60 & قبلى & \multirow{2}{*}{$\begin{array}{c}\text { اختبارتشتت الانتباه البعد } \\
\text { (الوصفى ) }\end{array}$} \\
\hline 5.16 & 84.30 & بعدى & \\
\hline 7.09 & 64.50 & قبلى & \multirow{2}{*}{ اختبار تشتت الانتباه البعد } \\
\hline 4.989 & 84.00 & بعدى & \\
\hline
\end{tabular}

ينص الفرض القائم عليه الاراسة الر اهنة على: 


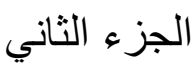

" توجد فروق فى المستوى المعرفي لاى الأطفال المصابين بالصرع قبل وبعد التدخل فى علاجهم بمضادات الصرع".

وللتحقق من صحة هذا الفرض قامت الباحثة باستخدام اختبار " ولكوكسون" Wilcocxon Signed Ranks Test الضابطة (مجمو عة التدخل بالدواء فقط) فى كل من : اختبار الذكاء، واختباركونرز (بعدا تشتت الانتباه: الوصفى، و التشخيصى)، وقياسات P300. ويتضح ذلك فى الجدول الآتى:

$$
\text { جدول (r) ( }
$$

اتجاه الفرق بين متوسط رتب القياسين القبلى والبعدى لدى أفر اد المجمو عة الضابطةعلى مقاييس

الذكاء، P300 كونرز لتشتت الانتباه (الوصفى و التشخيصى)

\begin{tabular}{|c|c|c|c|c|c|c|}
\hline \multirow{2}{*}{ مستوى } & \multirow[t]{2}{*}{ قيمة Z } & \multicolumn{2}{|c|}{ الرتب الموجبة (+) } & \multicolumn{2}{|c|}{ الرتب السالبة (-) } & \multirow[t]{2}{*}{ المقياس } \\
\hline & & المجموع & المتوسط & المجموع & المتوسط & \\
\hline$\because \cdot 1$ & $r_{.} \wedge \cdot V_{-}$ & - & • & 00 & 0.0 & اختبار الذكاء \\
\hline$\because .1$ & $r_{\text {r.A.r. }}$ & 00 & 0.0 & . & . & P300 \\
\hline$\because .1$ & Y.NIY- & 00 & 0.0 & . & . & كونرزلتشتت الانتباه \\
\hline$\because \cdot 1$ & r.AYL- & 00 & 0.0 & . & . & كونرزلتنتت الانتباه \\
\hline
\end{tabular}

من الجدول السابق يتضح وجود فروق دالة بين متوسطى رتب القياسين القبلى والبعدى لاى أفراد المجموعة الضـبطة حيث كان الفرق دال عند مستوى (1 . • ) على اختبار الذكاء، واختباركونرز (بعدا تشتت الانتباه: الوصفى، والتشخيصى)، وقياسات P300. لصالح القياس البعدى. (- n

\section{مناقشة النتائج : من العرض السابق للنتائج نجد أن:}

وجود فروق دالة بين متوسطى رتب القياسين القبلى والبعدى لدى أفراد مجموعة البحث حيث كان الفرق دال عند مستوى (1 •. •) على اختبار الذكاء، واختباركونرز (بعدا تشتت 


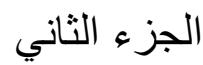

الانتباه: الوصفى، والتشخيصى)، وقياسات P300. لصالح القياس البعدى. مما يعنى أن الأطفال حدث لهم تدهور فى العمليات المعرفية التى تم قياسها عن طريق اختبار الذكاء، وبعدا تشتت الانتباه الوصفى، و التشخيصى لاختبار كونرز، وقياس p300.

ومن الملاحظ أيضا عدم تضارب نتائج تللك القياسات. حيث جاءت متسقة وتدعم بعضها بعضا، فقد لوحظ انخفاض فى مستوى الذكاء يقابله ارتفاع فى مستوى نتتت الانتباه الذى يقيسه مقياس كونرز الوصفى و التشخيصى، كما جاءت نتائج اختبار P300 مدعمة لتلك النتيجة. فقد وجدت فروق جوهرية فى طول زمن الرجع الذى يسبق استجابة الطفل للمثير ات، بما يعنى تر اجع القدرة على تركيز الانتباه وسر عة الاستجابة. و لاشك أن ذلك فى مجمله يدل على تراجع العمليات المعرفية للأطفال والتى ظهرت من خلال الفروق بين القياسات القبلية والبعدية، حيث تم القياس قبل التدخل بالعلاج مباشرة كقياس قبلى، ثم بعد سته أثنهر من التدخل بالعلاج الدوائى كقياس بعدى.

$$
\text { توصيات الدر اسة: }
$$

فى ضوء ما اسفرت عنه الدراسة الراهنة، يمكن تقديم مجموعة من التوصيات و المقترحات تستعرضها الباحثة فيما يلى:

ا ـ توجه الباحثين فى المجال النفسى بإجر اء المزيد من الأبحاث العلمية فى المجال الدوائى، للكثف عن مدى آثار العقاقير الطبية سواء السلبية كانت أم الإيجابية على النواحى المعرفية، أو النفسية ومن ثم تقديم البرامج التنموية المناسبة لتلك الحالات قبل حدوث

$$
\text { المشكلة التى قد يكون علاجها فيما بعد أصعب. }
$$

ץ- لعل فى نتائج الدراسة الر اهنة ما يؤكد بوضوح على ضرورة التعاون بين التخصصين النفسى والطبى فى علاج حالات الصرع وغيره من الاضطر ابات التى تحتاج إلى التدخل النفسى والطبى جنبا إلى جنب لمنع أى مشكلة معرفية أو نفسية محتملة الحدوث كآثار جانبية للمعالجات الدوائية. 


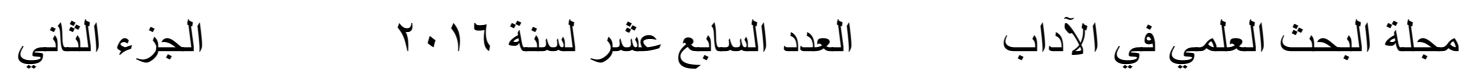

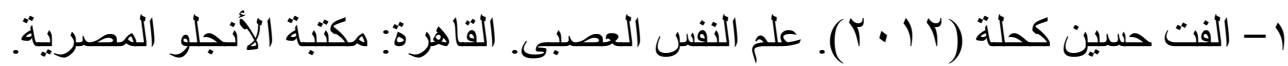

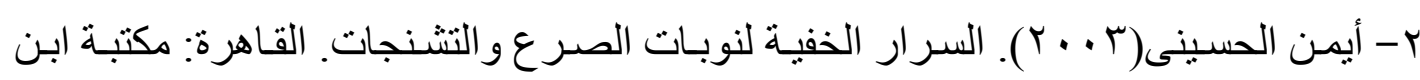
سينا.

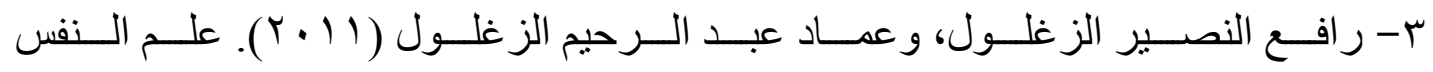

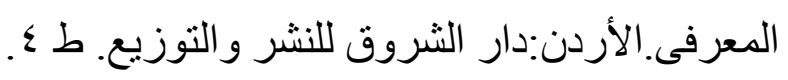




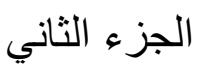

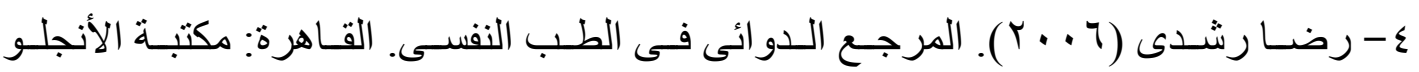

المصرية.

0- سـامى عبـد القوى (1997 (199). مـدخل إلـى علم الأدويـة النفسـية .القـاهرة: مكتبـة النهضــة

المصرية.

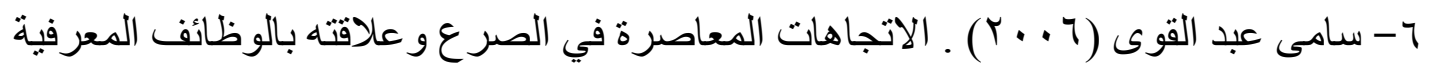

و العقلية والوجدانية ـ حوليات كلية الآداب جامعة عين شمس.

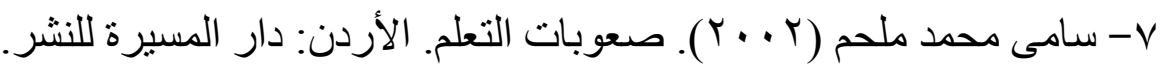

1 سليمان عبد الو احد يوسف ( • ب).المرجع فى صعوبات التعلم النمائية و الأكاديمية

و الاجتماعية والانفعالية. القاهرة: مكتبة الأنجلو المصرية.

9- سناء محمد سليمان (T · . ץ). سيكولوجية الفروق الفردية وقياسها. القاهرة: عالم الكتب.

• 1- عبد اللطيف موسى عثمان (991 (19). ما لاتعرفه عن الصرع. القاهرة:الجمع والتجهيز ات الفنية بالز هر اء للإعلام العربى.

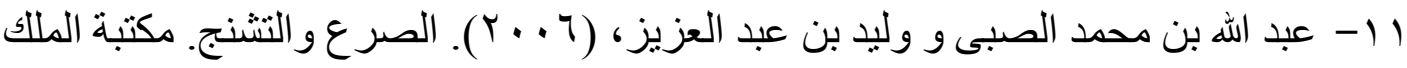

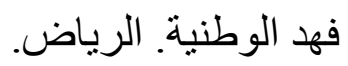

ץ ا - عدنان يوسف العتوم (ع . . ץ). علم النفس المعرفى النظريـة و التطبيـق ـ عمـان : دار المسيرة للنشر و التوزيع.

ب ا- فرج عبد القادر طه (س (99 ) ). موسوعة علم النفس و التحليل النفسى ـ الكويت : دار سعاد الصباح.

ع ا - فيونـا مارشـال، بـاميلا كروفورد (0 . ب). كيف تتغلب على الصـرع؟ . القاهرة: دار الفاروق للنشر.

0 للكمبيوثر و النشر و التوزيع.

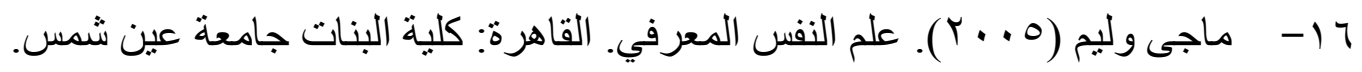

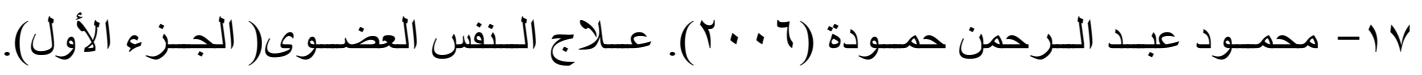
القاهرة:دون دار نشر.

18- Brandt C, Lahr D, May TW. (2014). Cognitive adverse events of topiramate in patients with epilepsy and intellectual disabilityjournal of epilepsy and behavior. 45: pp261-4. 
19- Brumbech L\& Sabers A., (2002). Effect of antiepileptic drugs on cognitive function in individuals with epilepsy: a comparative review of newer versus older agents. Journal of Drugs. 62(4)pp 593-604.

20- Clare M. Eddy, Hugh E. Rickards, \& Andrea E. Cavanna. (2011). The cognitive impact of antiepileptic drugs. Journal of Neurological Disorder . 4(6)pp 385-407.

21- Frawell J., Lee Y., Hirtz D.(1990). Phenobarbital for febril seizures- effects on intelligence and on seizure recurrence. Journal of new England Medicine, 322, pp364-369.

22- Gordon C ‘Edmund T and Christiana M (1987). Functional subdivisions of the temporal lobe neocortex.Journal of neu Helmstaedter C, Lendt M.(2001) Neuropsychological outcome of temporal end extratemporal lobe resection in children In: Jambaque I, Lassond M, Dulac O. eds: Neuropsychology of childhood epilepsy. Advances in behavioral Biology . Kluwer Academic/Plenum Press Boston (50); pp 215-227

23- Hermann BP, Seidenberg M, Schoenfeld J, Davies K.(1997). Neuropsychological characteristics of the syndrome of mesial temporal lobe epilepsy. Arch Neurol; 54(4) pp: 369-76.

24- Hessen E1, Lossius MI, Reinvang I, Gjerstad L.(2006). Influence of major antiepileptic drugs on attention, reaction time, and speed of information processing: results from a randomized, double-blind, placebo-controlled withdrawal study of seizure-free epilepsy patients receiving monotherapy. Journal of Epilepsia 47(12)pp 2038-45.

25- Holmes LB, Coull BA, Dorfman J, Rosenberger PB.،(2005).the correlation of deficits in IQwith midface and digit hypoplasia in 
children exposed in utero to anticonvulsant drugs . journal of pediatrics. 146(1):118-22.

26- Ijff D M., \&Aldenkamp AP.,(2013).Cognitive side-effects of antiepileptic drugs in children. Handbook of clinical neurology. (111) pp 707-718.

27- Meador KJ, Loring DW, Vahle VJ et al. (2005), Cognitive and behavioral effects of lamotrigine and topiramate in healthy volunteers. Journal of Neurology 64(12):2108-2114.

28- Motwani N, Afsar S, Dixit NS, Sharma N.(2015). Landau-Kleffner syndrome: an uncommon dealt with case in Southeast Asia. Journal of BMJ Case Report.: 10.1136/bcr-2015-212333.

29- Shannon HE.،Love PL.،(2007). Effect of antiepileptic drugs on learning as assessed by arepeated acquisition of response sequences task in rats. Journal of Epilepsy \&behavior.(1):16-25. 